\title{
Compared the Fight - or - flight system dependent people, glass, opium and ordinary on the basis of revised reinforcement sensitivity theory
}

\author{
Rezgar Majidi ${ }^{1, a}$, Yahya Yarahmadi ${ }^{2, b}$ * \\ ${ }^{1}$ Department of Psychology, Kurdestan Science and Research branch, Islamic Azad university, \\ Sanandaj, Iran. \\ 2* Department of Psychology, Sanandaj branch, Islamic Azad university, Sanandaj, Iran. \\ aMajidi.rezgar@gmail.com, bYyarahmadi@gmail.com
}

Keywords: Fight - or - flight System, dependence on the glass, dependence on opium, revised reinforcement sensitivity theory.

\begin{abstract}
This study aimed to compared the Fight - or - flight system dependent people, glass, opium and ordinary on the basis of revised reinforcement sensitivity theory. The present study method, of terms of purpose, function and of terms of manner of implementation, causalcomparative, of type then event. The study population included all drug addicts referred to the Medical Center Hospital of Sanandaj qods who first referred to the center (New Case) and have not received any medical treatment. Among the population of through available sampling a total of 90 people were selected and questionnaire Gary- Wilson personality questionnaire (GWPQ) 1993, was carried out on them. To analyze the data variance and Tukey test was used. The results showed that between the Fight - or - flight system dependent people, glass, opium and ordinary there is a significant difference. The results of analysis of variance showed that the level of significance (0.011) is less than $\% 5$, as a result of the confidence level $\% 95$, there difference, Between Fight - or - flight system level members dependents the opium, glass and ordinary people on the basis of revised reinforcement sensitivity theory.
\end{abstract}

\section{Introduction}

Skyrocketing drug trafficking is increasing in the world and this material will be dire consequences that directly threatens the youth and humanity [1]. Open international trafficking and addiction, millions of young people to kill and merchants of death and corruption, leads to wealth and power [2]. Health and social scourge of addiction is a big issue with many aspects of economic, political, cultural psychological, moral and legal [3]. The parents' awareness on the prevention and control of addiction dismal end it is an effective adjuvant. The gradual change in lifestyle with the progress of civilization, human welfare as the complications and problems occurring is higher. When using traditional and primitive people lived and their psychological problems and also some traditional solved But with today's lifestyle changes and new forms sometimes caused problems that it solves many of the people outside [4,5]. Mental diseases and it leads to the evolution of human behavior and habits that are sometimes very difficult and sometimes impossible to control and leave it. Human addiction to drugs and medications, including those used to them $[6,7]$.

According to the latest statistics in the country 5000000 people have experienced at least one drug and 2000000 people addicted to it. Progressive addiction and promote unhealthy methods such as injection drug use with shared needles leads to cure diseases such as AIDS, which has affected more than 70000000 people in the world and in our country, more than 14,000 people in the affected have. Decades of research has proved that the drug, the normal functioning of the brain's reward people were hurt. And continuous use of drugs leads to distortions in the brain reward system. Such deviations in brain tissue, neurotransmitters and brain information processing regional levels for drug use appears that the animal model and in humans has been demonstrated $[8,9]$.

Scoolar (2009) in a study of the impact of drug use on brain development in adolescents on adolescent consumption of fruit and marijuana and other drugs was conducted. In this study, adolescents who had substance and structure of brain function caused by drug use was evident with 
the changes [10]. Deop (2005) In a study known as executive function disorders in substance abusers among 35 patients addicted to alcohol, cocaine and methamphetamine and 35 healthy subjects, the addicts in a series of comparative cognitive behavioral, emotional and tasks compared to healthy subjects underperformed [11]. Etiology of brain systems behavior and addiction issues, separately, the two topics such as brain systems behavior that can have pervasive effects on a person's addiction and addicts on the other hand, these systems have behavioral brain the changes $[12,13]$. One of the core aspects of behavior that are considered in this study is the fight-flight system. War or escape system (FFS) clearly does not refer to a specific personality dimensions. Components of this system is overactive behavior associated with psychosis orientation, war (aggression defensive) and escape (dash from the source of punishment) is [14, 15]. In the field of addiction most attention is focused on behavioral activation system and more results of activity this system in humans arises the studies related to the neurotransmitter dopamine. Release of dopamine in the dopaminergic pathway associated with behavioral activation system is associated with the movement program of this system $[5,16]$. Thus, according to the mentioned issues in this research sought to investigate this issue. Whether are there differences between Fight - or - flight system dependent glass, opium and ordinary?

\section{Research Methodology}

The present study method, of terms of purpose, function and of terms of manner of implementation, causal-comparative, of type then event. given that, in this study, we plan, variable the Fight - or - flight system dependent people, glass, opium and ordinary compared, causalcomparative method in mode is useful. Since these features are already happened. so the causalcomparative method of then event. The population of this study included all drug addicts referred to the Medical Center Hospital of Sanandaj Gods who first referred to the center (New Case) and have not received any medical treatment. And ordinary people through patients referred to ENT clinic and Medical Center Hospital of Tawhid Sanandaj were selected. Using available sampling. so that of each patient referring to the center if the previously untreated patients and for the first time referred to the center, of the consent, according to the prevailing usage in one group were related to opium or glass.

Was used, in this study, the formula for determining the sample size Cochran - Cox.

$$
n=(N \times t 2 \times p \times q) \div(N \times d 2+t 2 \times p \times q)
$$

The maximum permissible error $(\mathrm{d})$ is considered equal to 0.05 , confidence coefficient $0.95, \mathrm{t}=$ 1.96 , and the values of $\mathrm{p}$ and $\mathrm{q}$ are each equal to 0.5 . $\mathrm{P}$ values are considered equal to 0.5 (3). So based on the above formula, 90 people were considered in three 30-people groups (30 person, dependent on glass, 30 person, dependent on opium and 30 person, normal people).

\section{Method of the research practice}

In this study, after the selection of samples that the samples were selected from among those who quit for the first time to the Medical Center Hospital of Gods to leave within 6 months of the year 93 admitted. the initial interview was conducted by researchers if they satisfy the criteria for inclusion to the questionnaire was presented to them, the questionnaire was completed in the presence of the researcher, to select the sample of patients referred to ENT Clinic Medical Center Hospital Tawhid Sanandaj that do not have a history of any drug samples were selected. 


\section{Research Tools}

Gary- Wilson personality questionnaire (GWPQ):

Gary - Wilson personality questionnaire the amount activity system in the brain-behavior and assesses their components it is a self-assessment personality questionnaire, Wilson, Barrett and Gary have designed it in 1989 and consists of 120 articles .According to the Gary's theory of personality, there are three separate systems - but interact with each other - in the brains of mammals, that's control exciting behavior.. The predominance of the activity of each of these systems in person, it is resulting to different exciting states such as soon anxiety, arousal and fear and excites ways to confront and different behavioral responses. Gary's cognitive theory is based on the principle that individual differences in personality reflect differences in the sensitivity of the BAS and BIS [16]. According to the Gary's theory of sensitivity to reinforce two exciting system by adjusting the sensitivity person the threats and incoming rewards informed the Character. This questionnaire that evaluates activity of brain systems behavior and assesses its components, a selfassessment questionnaire of personality designed by Wilson and Gary and Barrett in the UK and psychometric properties in addition to Britain also assessed of the two countries, Japan and Russia. The questionnaire was translated into Persian by Azadfallah et al (1999), and has been implemented of 211 people in a group of Iranian students. This scale evaluates amount activity in the brain / behavior systems and component of them, and contains 120 articles, to evaluate each of the behavioral activation systems, behavioral inhibition and fight / escape were considered 40 items. Of 40 items related to behavioral inhibition system activity devoted 20 of the component to avoid possible action And 20 of the components blackout, 40 articles on behavioral activation system activity have been avoided 20 of intention components and 20 of the active Avoidance components Finally, Article 40 of the anti-system activity / escape activity have been avoided 20 of the components of the conflict and 20 of the component escape [16].

\section{Method analysis the data}

The descriptive analysis of the data, from the mean, standard deviation and descriptive tables for analysis inferential data, and research to investigate questions of independent one-way variance analysis and Tukey test. In order to answer the questions of descriptive and inferential statistical analyzes were performed using SPSS 22 software.

\section{Findings}

As shown in Table 1, Descriptive Index, the average Fight - or - flight system in the opium group 41.83, and in the glass group 43.17, and in the ordinary people 41. Also the standard deviation Fight - or - flight system in the opium group 5.10, and in the glass group 8.86, and in the ordinary people 6.32 .

Table 1. Descriptive information Fight - or - flight system

\begin{tabular}{|c|c|c|c|c|}
\hline \multirow{2}{*}{$\begin{array}{c}\text { Fight }- \text { or }- \\
\text { flight } \\
\text { system }\end{array}$} & group & Abundance & mean & $\begin{array}{c}\text { Standard } \\
\text { deviation }\end{array}$ \\
\cline { 2 - 5 } & Opium & 30 & 41.83 & 5.10 \\
\cline { 2 - 5 } & Glass & 30 & 43.17 & 8.86 \\
\cline { 2 - 5 } & Ordinary People & 30 & 41 & 6.32 \\
\hline
\end{tabular}

Question: there does difference between the Fight - or - flight system dependent people, glass, opium and ordinary on the basis of revised reinforcement sensitivity theory? 
Table 2. Results of one-way variance analysis about Fight - or - flight system level, members dependents the opium, glass and ordinary people

\begin{tabular}{|c|c|c|c|c|c|}
\hline $\begin{array}{c}\text { The origin of the } \\
\text { dispute }\end{array}$ & SS & df & MS & F & sig \\
\hline Between-group & 306.23 & 2 & 153.11 & 3.47 & 0.011 \\
\hline Within the group & 3126.14 & 87 & 44.07 & & \\
\hline Total & 3435.36 & 89 & & & \\
\hline
\end{tabular}

The results of analysis of variance showed that the level of significance (0.011) is less than $\% 5$, as a result of the confidence level \%95, there difference, Between Fight - or - flight system level members dependents the opium, glass and ordinary people on the basis of revised reinforcement sensitivity theory.

Table 3. Results of Tukey test for Fight - or - flight system, members dependents the glass, opium and ordinary

\begin{tabular}{|c|c|c|c|}
\hline Variable & $\begin{array}{c}\text { mean } \\
\text { difference }\end{array}$ & $\begin{array}{c}\text { standard } \\
\text { deviation }\end{array}$ & sig \\
\hline glass & 8.33 & 1.79 & 0.88 \\
\hline opium & $4.33^{* *}$ & 1.79 & 0.046 \\
\hline ordinary & $5.16^{* *}$ & 1.79 & 0.014 \\
\hline ** The mean difference is significant at the \\
0level of 0.01 \\
\hline
\end{tabular}

On based, Tukey test results, there significant differences between Fight - or - flight system dependent people of glass, and dependent people of opium with ordinary people. But significant difference was not observed between dependent people opium with dependent people of glass. also descriptive data also confirm that there significant differences between the mean and standard deviation the Fight - or - flight system dependent people, glass and opium with ordinary on the basis of revised reinforcement sensitivity theory.

\section{Discussion and Conclusion}

According to the results obtained in this research it can be said that there is a significant difference between the Fight - or - flight dependent on system of glass and ordinary and opium according to revised Gary's strengthen to sensitivity. The results of analysis of variance showed that the level of significance $(0.011)$ is less than $\% 5$, as a result of the confidence level $\% 95$, there difference, Between Fight - or - flight system level members dependents the opium, glass and ordinary people on the basis of revised reinforcement sensitivity theory. To explain these findings, it can be argued that opium addicts made conditional and unconditional annoying to drivers, the fightor-flight response system they use. The pattern has been revised to strengthen the ecological sensitivity and Mac Nugget (2000), primates in particular, three-threatening behavioral response shows that include the avoidance, evasion and freezing. Various studies have shown that threatening situations, which threaten human survival, causing fear in most of them. While the office and depot (1999) showed that the degree of clarity and fear arousal threatening situation (and not the type of threats). In other words, social situations trigger fear in people, often the size of the physical risks, destructive and threatening to have. And on the other hand according to Ahman (1986), threatening social situations can also cause personal injuries in the province. So waxes fear, people close to risk perception, a cognitive structure that individuals are affected by personality differences. 


\section{Reference}

[1] Wilson, R.D. Gray, G. A, Barrett, P.T, A factor analysis of Gray-Wilson personality questionnaire, 1990, Personality and Individual Differences, 11(10), 37- 44.

[2] Gray, J. A, Framework for taxonomy of psychiatric disorders, In S. Van. Goozen, Depoll and J. Sergeant (Eds), Emotions, Essay on Emotion Theory, UK: Lawrance Erlbaum, 1994.

[3] Kimbrel NA, Nelson-Gray RO, Mitchell JT. Reinforcement sensitivity and maternal style as predictors of psychopathology. Personality and Individual Differences, 42 (2007), 1139-1149.

[4] Hundt. N.E, Kimbrel, N. A, Mitchell. J. T, Nelson, Grey. R. O, High BAS but not low BIS, predicts externalizing symptoms in adults. Personality and Individual Differences, 2008, (44) 563573.

[5] Johnson, S. L, Turner, R. J, Iwata, N, BAS/BIS levels and psychiatric disorder/An epidemiological study, J. Psychopathol Behav., 2008, 25-36.

[6] Kazemi, H., Mortazavi, S., victims, M., E., (1393). Comparison of brain-behavior mechanisms Maintenance treatment of patients with substance abuse and healthy people. Addiction Research.

[7] Pickering, A, Corr, P. J. A, Gray's reinforcement sensitivity theory (RST) of personality, In G. Boyle, G. Matthews, D. Saklofske (Eds.), The SAGE handbook of personality theory and assessment, Personality theories and models, 2008, (1) 239 - 257.

[8] Alimoradi, Abdul Latif, Alert S., Scholastic Ghorori M. Comparison of the activity of brain systems - behavioral and Mental health, drug abusers and normal individuals. Journal of Mental Health.

[9] Knyazev, G. G, Slobodskaya H. R, Wilson, Glenn, D, Comparison of the construct validity of the Gray-Wilson Personality Questionnaire and the BIS/BAS scales, Personality and Individual Differences, 37 (2004), 1565-1582.

[10] Michel, S, Regionally effects of nicotine, Eur. J. Pharmacol., 1998, 167 (3), 311 - 322.

[11] Depue, R. A., Collins, P. F. (1999). Neurobiology of the structure of personality: Dopamine, facilitation of incententive motivation, and extraversion. Behavioral and Brain Sciences, 22, pp.491569.

[12] Pourmohsen Stubble, Angel, Asadi, Angel, Haghshenas. Activity of brain systems and behavior and differences Sex addicts and non-addicts. Journal of Cognitive Science news - Seyed Kamal Kharrazi - Research.

[13] Corr, P. J. Reinforcement sensitivity theory and personality. Journal of Neurosciences \& Biobehavioral Reviews, 28 (2004), 317-332.

[14] Sarmad, Z. Hejazi, E, Bazargan, A, Behavioral science research methods, Agah, Tehran, 2008. [15] Abdollahzadeh Serious, Aida, Hashemi Nosratabad, T., Mrayd AR; Allah, F. The role of brain systems - behavior Forecast substance abuse. Journal of Clinical Psychology.

[16] Gray, J. A, Brain systems that mediate both emotion and cognition, Cogn. Emotion, (1993), (4) $269-288$. 